\title{
Surgical indication for congenital tracheal stenosis complicated by pulmonary artery sling
}

\author{
Atsushi Harada, Naoki Shimojima, Akihiro Shimotakahara, Saya Azuma, Yoshiaki Ishizuka, Hirofumi \\ Tomita, Seiichi Hirobe \\ Department of Surgery, Tokyo Metropolitan Children's Medical Center, Tokyo, Japan \\ Contributions: (I) Conception and design: A Harada; (II) Administrative support: A Harada; (III) Provision of study materials or patients: A Harada; (IV) \\ Collection and assembly of data: A Harada; (V) Data analysis and interpretation: A Harada; (VI) Manuscript writing: All authors; (VII) Final approval \\ of manuscript: All authors. \\ Correspondence to: Naoki Shimojima, MD, PhD. Department of Pediatric Surgery, Tokyo Metropolitan Children's Medical Center 2-8-29 Musashi- \\ dai, Fuchu-Shi, Tokyo 183-8561, Japan. Email: naoki.shimojima@gmail.com.
}

\begin{abstract}
Background: Congenital tracheal stenosis (CTS) is a rare and life-threatening disease in children. Although pulmonary artery sling (PA sling) complicated by CTS sometimes occurs, there are few reports detailing the management of CTS with PA sling. The purpose of this retrospective study was to determine the appropriate indications for surgical intervention for CTS complicated by PA sling.

Methods: We evaluated 42 patients (19 males and 23 females) with the median age of $9.9 \pm 3.3$ months (range, 5-34 months) with CTS complicated by PA sling who were treated at our hospital between 2005 and 2018. Twenty-eight patients received both a slide tracheoplasty and PA re-implantation, and 14 patients were managed conservatively for CTS. Among the latter, nine patients received PA re-implantation only, and five were managed conservatively without any surgery. We determined the surgical indications by retrospectively comparing the DLR value [tracheal diameter $(\mathrm{mm})$ /stenotic length ratio], history of ventilator respiration, mortality rate, and post-operative course of patients at a single institution.
\end{abstract}

Results: The cut-off value for the DLR was determined to be 5.9 (sensitivity: 0.929, specificity: 0.714 ) by using the ROC curve (AUC 0.89, $\mathrm{P}<0.05$ ).

Conclusions: A DLR value under 5.9 may serve as a new surgical indication for CTS complicated by PA sling.

Keywords: Pulmonary artery sling; congenital tracheal stenosis (CTS); tracheoplasty

Submitted May 21, 2019. Accepted for publication Oct 17, 2019.

doi: $10.21037 /$ jtd.2019.11.31

View this article at: http://dx.doi.org/10.21037/jtd.2019.11.31

\section{Introduction}

Congenital tracheal stenosis (CTS) is a rare and lifethreatening disease in children and is characterized chiefly by narrowing of the tracheal tract due to complete tracheal rings and the absence of the membranous component (1). Pulmonary artery sling (PA sling) is also a rare condition in which the left pulmonary artery originates in the right pulmonary artery and passes between the trachea and esophagus, leading to the formation of a vascular ring which surrounds and compresses the trachea (2). PA sling is complicated by CTS at a rate of 50-65\% $(3,4)$, and children with PA sling who do not require tracheal surgery have excellent outcomes (5). Chen (6) reported that the tracheal diameter in patients who are managed conservatively for CTS may approach that of heathy children by age 7-9 years; hence the surgical indications for CTS with minor symptoms need to be assessed carefully due to the $15-26 \%$ risk of mortality associated with surgical interventions $(3,7)$. Huang et al. (8) reported a tracheal diameter of $3 \mathrm{~mm}$ as a cut off for surgical treatment of CTS complicated with PAS while Anton-Pacheco (9) 


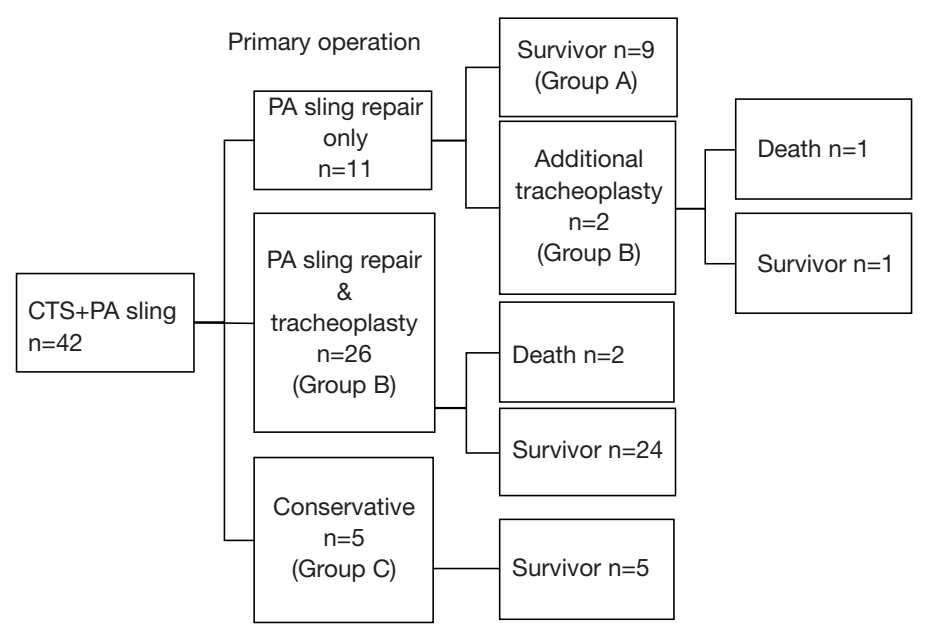

Figure 1 Flow chart of CTS complicated with pulmonary artery (PA) sling management and outcome (n=number of patients). Conservative group, n=14 (Group A\&C); surgical group, n=28 (Group B).

reported that patients with a $4-6 \mathrm{~mm}$ tracheal diameter and minor symptoms can be managed conservatively. However, there is still no accurate treatment protocol due to the lack of sufficient evidence (10). The aim of this study was to determine the appropriate management of CTS complicated by PAS and to suggest a standard surgical indication based on a retrospective analysis of 42 patients at a single center.

\section{Methods}

\section{Patient demographics}

Forty-two patients with CTS complicated by PAS were treated at our center between 2005 and 2018. These patients were categorized into three groups (Figure 1): Group A, consisting of nine patients who received PA re-implantation only; Group B, consisting of 28 patients who received both slide tracheoplasty and PA re-implantation; and Group C, consisting of five patients who were managed conservatively without any surgical intervention. In Group B, two patients received PA re-implantation only as their primary operation (Figure 1) although additional tracheoplasty was needed due to respiratory dysfunction. In summary, 14 patients were managed conservatively for CTS (conservative group: group $A+C$ ), and 28 patients received both a slide tracheoplasty and PA re-implantation (surgical intervention group: group B).

The diagnosis of CTS was based on clinical as well as bronchoscopic and radiologic findings (enhanced CT), which revealed complete cartilage rings.

\section{Tracheal diameter and measurement method}

The lumen diameter of the most stenotic part of the trachea in each patient was measured using CT images (in millimeters) according to the method described by Griscom et al. (11). The stenotic length ratio was defined as the ratio of the length of the stenotic segment to the full length of the trachea and was measured by enhanced CT. The total tracheal length was defined as the length of the segment from the carina to the lower border of the fourth cervical vertebra, as the bottom of the cricoid cartilage in the infant lies opposite the vertebra (12).

\section{Predictive factors for surgical indication}

We compared the conservative intervention groups (Groups A \& C) and the surgical intervention group (Group B) in terms of their background, CT findings, respiratory symptoms, mortality rate, and DLR (diameter/length ratio). DLR was defined as the ratio of the narrowest diameter/ stenotic segment length to the total tracheal length [tracheal diameter $(\mathrm{mm}) /$ stenotic length ratio]. The DLR value was reported by Hong et al. (13) in 2015 as a potentially reliable indication for surgery in CTS complicated by PA sling. Receiver operating characteristic (ROC) curve analysis was used to identify the cut-off value for surgical treatment of 
CTS complicated by PA sling.

\section{Surgical management of CTS complicated by a PA sling}

All the patients in the present study had CTS with complete cartilage rings and compression due to a PA sling. The surgical indication for these patients was based on our hospital protocol, which stipulates a tracheal diameter $<3 \mathrm{~mm}$ and a tracheal length ratio $>60 \%$. Recurrent airway symptoms, the clinical course, such as a past history of intubation and pulmonary blood flow scintigraphy, were also considered.

Surgery-related mortality was defined as death occurring within 30 days after surgery or before hospital discharge. The surgical management of CTS consisted of a slide tracheoplasty in all cases, and the surgical treatment for PA sling was PA re-implantation consisting of the anastomosis of the left pulmonary artery on the pulmonary trunk.

\section{Statistical analysis}

Continuous and categorical variables were expressed as the mean standard deviation (SD) and frequency (\%), respectively. The Fisher's exact test and Mann-Whitney $\mathrm{U}$ test were used for categorical variables to compare data between the surgical and conservative intervention groups. The cut-off value was determined by maximizing the sum of the sensitivity and specificity on Youden's index. The confidence interval for sensitivity and specificity were calculated by binomial test. $\mathrm{P}<0.05$ was considered statistically significant. All the data were analyzed using IBM $^{\circledR}$ SPSS $^{\circledR}$ ver. 25.

\section{Results}

This study included 42 patients [19 males (45.2\%) and 23 females $(54.8 \%)$ ], with the median age of $9.9 \pm 3.3$ months (range, 5-20 months). In the conservative group (Group $\mathrm{A} \& \mathrm{C})$, the median age was $9.9 \pm 10.4$ months, the median weight was $6.4 \pm 2.6 \mathrm{~kg}$, the tracheal diameter was $4.5 \pm 0.7 \mathrm{~mm}$, the cardiac abnormality rate was $7 / 14(50 \%)$, the mortality rate was $0 / 14(0 \%)$, and the history of intubation was $2 / 14(14 \%)$. The characteristics of all the patients in the conservative management group (Groups A \& C) and of two patients in Group B who received additional tracheoplasty after PA re-implantation are shown in Table 1.

In the surgical management group (Group B), the median age was $7.4 \pm 4.7$ months, the median weight was
$5.9 \pm 1.8 \mathrm{~kg}$, the tracheal diameter was $2.8 \pm 0.5 \mathrm{~mm}$, the cardiac abnormality rate was $13 / 28(47 \%)$, the mortality rate was $3 / 28(12 \%)$, and the history of intubation was $14 / 28(50 \%$ ) (Table 2). These three patients died of mediastinitis due to anastomotic leakage. The DLR [tracheal diameter/stenotic length ratio (\%)] differed significantly between the conservative treatment (Group A \& C) and surgical treatment groups (Group B). History of ventilator use and the tracheal diameter also differed significantly between the groups. The age, body weight, mortality rate, stenotic length ratio, and congenital cardiac abnormality rate (\%) associated with CTS did not differ significantly between groups (Table 2). The cut-off value of the DLR, which determined whether a slide tracheoplasty should be performed for CTS complicated with PA sling, was evaluated by using the ROC curve (AUC 0.89, $\mathrm{P}<0.05$ ) and was determined to be 5.9 (sensitivity: 0.929 , specificity: 0.714) (Figure 2) A comparison of respiratory symptoms associated with CTS between the DLR $\geq 5.9$ and DLR $<5.9$ groups is shown in the Table 3. The sensitivity and specificity of DLR $<5.9$ for intubation history was $62 \%$ $(13 / 21)$ and $68 \%(17 / 25)$, respectively.

\section{Discussion}

CTS complicated by PA sling (PAS) is a rare condition in the neonatal and infancy periods causing airway obstruction due to complete cartilage rings surrounded by a PA. Tracheomalacia due to compression of the vascular ring is also a risk factor for mortality (14). Furthermore, Cohen et al. (4) reported that patients with CTS associated with PA sling frequently presented with cardiac abnormalities; thus, the treatment strategy is complicated, and there is no consensus yet on treatment due to the lack of sufficient evidence. Yamaguchi and Oshima $(14,15)$ suggested that both PA reimplantation and tracheoplasty be performed in patients with CTS associated with PA sling presenting moderate or more severe clinical symptoms. Anton-Pacheco (9) reported that patients with a tracheal diameter of 4-6 $\mathrm{mm}$ and minor symptoms can be managed conservatively. On the other hand, Backer et al. (5) recommended a tracheoplasty be performed. Huang et al. (8) recommended that patients receive a tracheoplasty if the tracheal width is under $3 \mathrm{~mm}$. The latter recommendation was adopted at our institution, but our experience has shown that a tracheal diameter of $3.7 \mathrm{~mm}$ (Case B-2. Table 1) requires additional tracheoplasty; hence not only the tracheal diameter, but also the tracheal length, should be carefully 
Table 1 Characteristics of all the patients in the conservative management group (Groups A \& C), and of two patients in Group B who received additional tracheoplasty after PA re-implantation

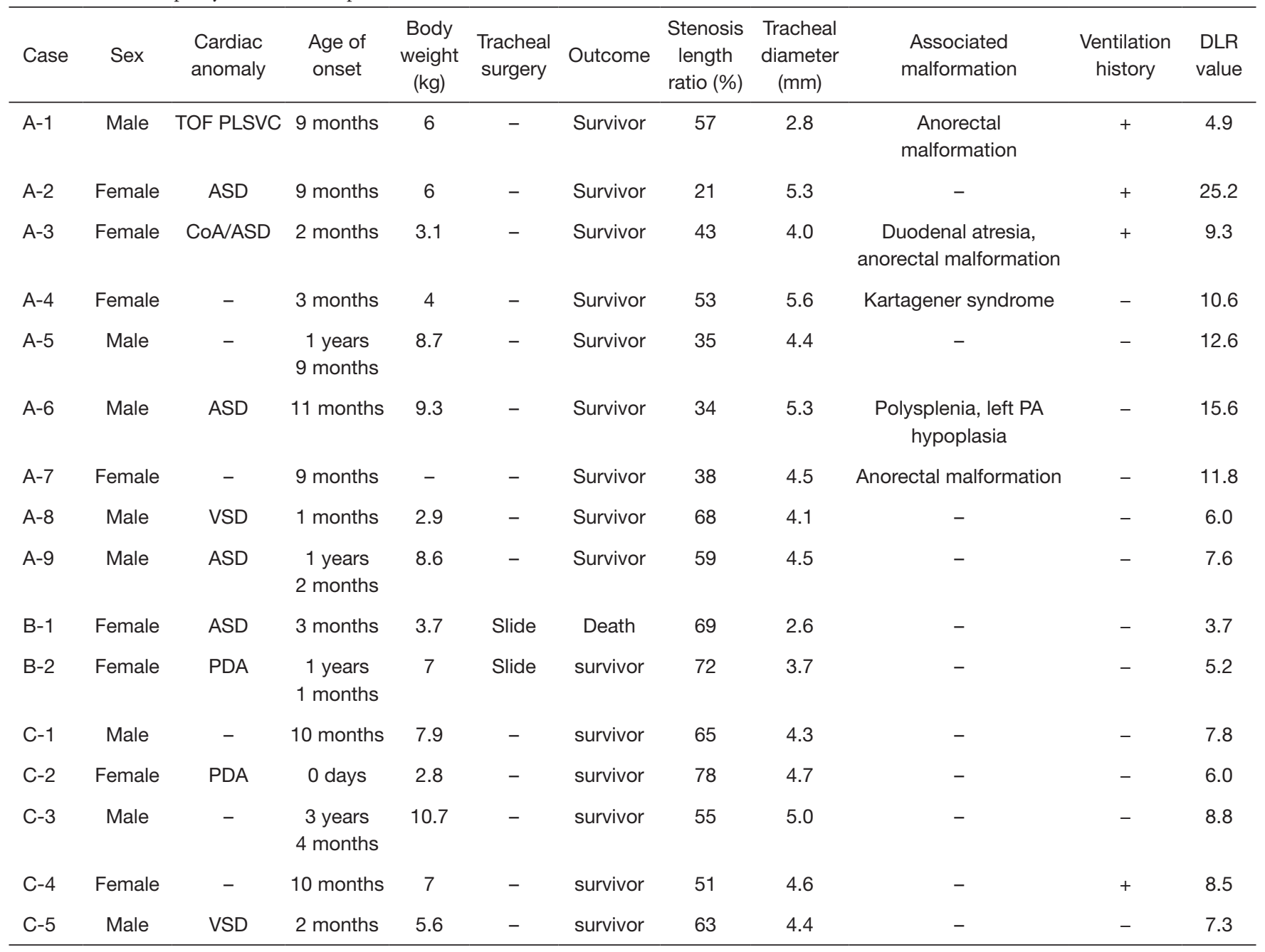

TOF, tetralogy of Fallot; CoA, coactation of the aorta; PLSVC, persistent left superior vena cava; ASD, atrial septal defect; VSD, ventricular septal defect; PDA, patent ductus arteriosus; PA, pulmonary artery.

Table 2 Background and DLR values of conservative management and surgical management groups

\begin{tabular}{|c|c|c|c|}
\hline Patients data & Conservative management (Group A + Group C) & Surgical management (Group B) & $P$ value \\
\hline Age (months) & $9.9 \pm 10.4$ & $7.4 \pm 4.7$ & 0.749 \\
\hline Body weight (kg) & $6.4 \pm 2.6$ & $5.9 \pm 1.8$ & 0.604 \\
\hline Tracheal diameter (mm) & $4.5 \pm 0.7$ & $2.8 \pm 0.5$ & $<0.05$ \\
\hline Cardiac abnormality & $7 / 14(50 \%)$ & $13 / 28(47 \%)$ & 0.827 \\
\hline Mortality rate & $0 / 14(0 \%)$ & $3 / 28(12 \%)$ & 0.204 \\
\hline History of intubation & $2 / 14(14 \%)$ & $14 / 28(50 \%)$ & $<0.05$ \\
\hline DLR (diameter/length ratio) & $10.1 \pm 5.2$ & $5.3 \pm 2.0$ & $<0.05$ \\
\hline
\end{tabular}


assessed when considering surgical intervention. Hong et al. (13) reported that the DLR (diameter/length ratio) may be a more reliable indicator for surgical intervention. The DLR reflects the severity of the CTS based on the tracheal diameter and the length of the stenotic tracheal segment. In our study, the DLR significantly differed between the conservative and surgical treatment groups. The cut-off value was determined by using the ROC curve (AUC 0.89, $\mathrm{P}<0.05$ ). Most of our conservative cases met this criterion. Patient A-1 (Table 1) had a DLR of 4.9, and we suggested that she receive a slide tracheoplasty based on the tracheal diameter and symptoms, but her parents refused. She is currently alive with only minor airway symptoms despite requiring respiratory ventilator management twice after PA re-implantation. The appropriate intervention in

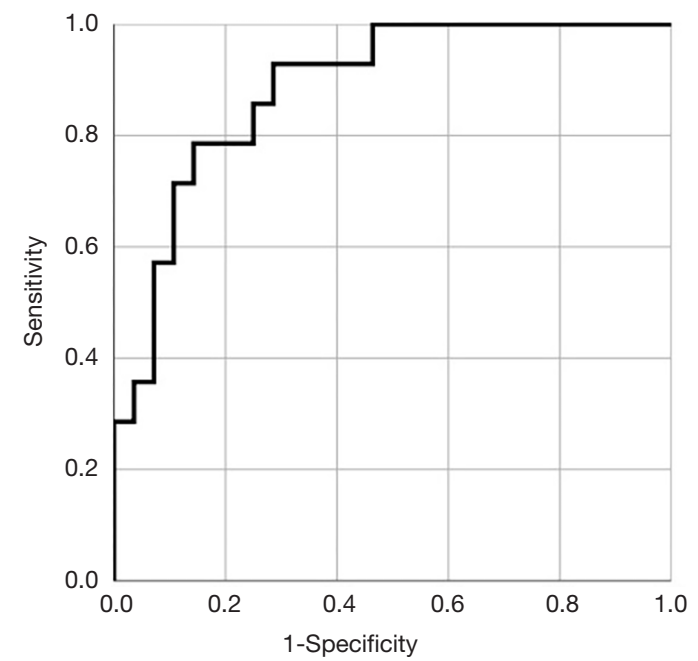

Figure 2 ROC curve was evaluated to determine the surgical indication. The AUC was 0.89 ( $\mathrm{P}<0.05,95 \%$ CI: 0.785-0.985). this case was most likely a slide tracheoplasty.

In contrast, the DLR value in the two patients with an additional tracheoplasty (Case1-B, Case2-B, Table 1) was 3.7 and $5.2(<5.9)$, clearly indicating the need for a slide tracheoplasty during the primary operation. The cut-off value proposed herein, based on our experience of these cases, may serve as an indication for nonsurgical intervention.

In addition, we evaluated the relationship between the DLR value and airway symptoms. The DLR $<5.9$ group tended to have severe airway dyspnea and more instances of intubation. However, the specificity and sensitivity may not be high enough for DLR $<5.9$ to serve as a useful indicator of airway symptoms.

This study has some limitations. This study was retrospective, and the recommendations as to the predictive value of the DLR are based on limited experience. In addition, the stenotic length of the tracheal segment may have a disproportionate influence on DLR values although Brouns et al. (16) reported that computational flow-dynamics studies demonstrated that the degree of stenosis rather than the length of the stenotic segment is the main factor in the decrease in airway pressure, which is chiefly responsible for the airway symptoms. Therefore, the predictive value of the DLR requires more detailed assessment in future prospective studies.

\section{Conclusions}

The method of managing CTS complicated by PAS is still unclear. Our study showed that the lumen diameter and length of the stenotic tracheal segment are important factors in deciding the appropriateness of surgical intervention. A DLR $<5.9$ may be a reliable surgical indication for a slide tracheoplasty.

Table 3 Relationship between DLR value and airway symptoms in conservative management and surgical management groups

\begin{tabular}{|c|c|c|c|c|}
\hline Airway symptom & \multicolumn{2}{|c|}{ Conservative management $(n=14)$} & \multicolumn{2}{|c|}{ Surgical management $(n=28)$} \\
\hline Dyspnea & 0 & 2 & 8 & 2 \\
\hline Wheezing & 1 & 9 & 8 & 6 \\
\hline Cyanosis & 0 & 0 & 2 & 0 \\
\hline No symptom & 0 & 2 & 0 & 0 \\
\hline History of intubation & 1 & 2 & 12 & 2 \\
\hline
\end{tabular}




\section{Acknowledgments}

The authors would like to thank Mr. James Robert Valera for his assistance with editing this manuscript.

\section{Footnote}

Conflicts of Interest: The authors have no conflicts of interest to declare.

Ethical Statement: The authors are accountable for all aspects of the work in ensuring that questions related to the accuracy or integrity of any part of the work are appropriately investigated and resolved. All procedures performed in studies involving human participants were in accordance with the ethical standards of the institutional research committee and with the 1964 Helsinki declaration and its later amendments or comparable ethical standards. Formal consent was not required. This article does not contain any studies with animals performed by any of the authors. The study was approved by institutional ethics committee/ethics board of H30b-209.

\section{References}

1. Kouchoukos NT, Blackstone EH, Hanley FL, et al. Kirklin/Barratt-Boyes Cardiac Surgery. 4th ed. Philadelphia, USA: Elsevier Saunders, 2013:1845-47.

2. Hofferberth SC, Watters K, Rahbar R, et al. Management of congenital tracheal stenosis. Pediatrics 2015;136:e660-9.

3. Berdon WE, Barker DH, Wung JT, et al. Complete cartilage-ring stenosis associated with anomalous left pulmonary artery: the ring-sling complex. Radiology 1984;152:57-64.

4. Cohen SR, Landing BH. Tracheostenosis and bronchial abnormalities associated with pulmonary artery sling. Ann Otol Rhinol Laryngol 1976;85:582-90.

Cite this article as: Harada A, Shimojima N, Shimotakahara A, Azuma S, Ishizuka Y, Tomita H, Hirobe S. Surgical indication for congenital tracheal stenosis complicated by pulmonary artery sling. J Thorac Dis 2019;11(12):5474-5479. doi: $10.21037 /$ jtd.2019.11.31
5. Baker CL, Russell HM, Weber TR, et al. Surgical treatment of pulmonary artery sling and tracheal stenosis. Ann Thorac Surg 2005;79:38-46.

6. Cheng $\mathrm{W}$, Manson DE, Forte $\mathrm{V}$, et al. The role of conservative management in congenital tracheal stensosis: an evidence-based long term follow-up study. J Pediatr Surg 2006;41:1203-7.

7. Butler CR, Speggiorin S, Rojiberg FM, et al. Outcome of slide tracheoplasty in 101 children: a 17-year single-center experience. J Thorac Cardiovasc Surg 2014:147:1783-9.

8. Huang SC, Wu ET, Wang CC, et al. Surgical management of pulmonary artery sling: trachea diameter and outcomes with or without tracheoplasty. Pediatr Pulmonol 2012;47:903-8.

9. Anton-Pacheco JL. Tracheobronchial stents in children. Semin Pediatr Surg 2016;25:179-85.

10. Arcieri L, Giordano R, Murzi B. To do or not to do? The management dilemma of congenital tracheal stenosis in the setting of the ring-sling complex. J Thorac Dis 2017;9:4896-8.

11. Griscom NT, Wohl MED. Dimensions of the Growing Trachea Related to Age and Gender. AJR Am J Roentgenol 1986;146:233-7.

12. Adewale L. Anatomy and assessment of the pediatric airway. Paediatr Anaesth 2009;19:1-8.

13. Hong X, Zhou G, Liu Y, et al. Management of pulmonary artery sling with tracheal stenosis: LPA re-implantation without tracheoplasty. Int J Clin Exp Med 2015;8:2741-7.

14. Oshima Y, Yamaguchi M, Toshomura N, et al. Management of pulmonary artery sling associated with tracheal stenosis. Ann Thorac Surg 2008;86:1334-8.

15. Yamaguchi M, Ohashi H, Hosokawa Y, et al. Surgical treatment of airway obstruction associated with congenital heart disease in infants and small children. Eur J Cardiothorac Surg 1991;5:479-85.

16. Brouns M, Jayaraju ST, Lacor C, et al. Tracheal stenosis: a flow dynamic study. J Appl Physiol 2007;102:1178-84. 